\title{
INSTAGRAM PANAHAN KOREA SELATAN PADA OLIMPIADE TOKYO 2020 DALAM PERSPEKTIF DETERMINISME TEKNOLOGI
}

\author{
Teguh Dwi Putranto \\ Ilmu Sosial, Fakultas Ilmu Sosial Dan Ilmu Politik, Universitas Airlangga \\ J1. Dharmawangsa Dalam, Surabaya \\ Email: teguh.dwi.putranto-2019@fisip.unair.ac.id
}

\begin{abstract}
ABSTRAK
Prestasi Korea Selatan pada cabang olahraga Panahan sudah tidak diragukan lagi dalam berbagai kompetisi olahraga tingkat internasional. Atlet Panahan Korea Selatan baik di sektor putra maupun putri mendominasi di setiap kompetisi yang diikuti. Bahkan di setiap Olimpiade sebagai ajang olahraga multi event empat tahunan, keberadaan Korea Selatan pada cabang olahraga Panahan tidak bisa dipandang remeh. Penelitian ini bertujuan untuk mengetahui bagaimana penggunaan Instagram Panahan Korea Selatan pada Olimpiade Tokyo 2020 dalam perspektif determinisme teknologi. Metode yang digunakan dalam penelitian ini adalah content analysis Krippendorff dengan pendekatan kuantitatif pada postingan Instagram @koreaarchery_official periode 23 Juli 2021 sampai 31 Juli 2021. Kesimpulan dari penelitian ini adalah bahwa Instagram @koreaarchery_official digunakan untuk memberikan apresiasi kepada para pemanah Korea Selatan dan memunculkan sportivitas masyarakat digital dan masyarakat Korea Selatan pada khususnya selama penyelenggaraan Olimpiade Tokyo 2020.
\end{abstract}

Kata kunci: Panahan, korea selatan, Olimpiade Tokyo 2020, media, olahraga.

\begin{abstract}
South Korea's achievements in the sport of archery are unquestionable in various international sports competitions. South Korean archery athletes in both the men's and women's sectors dominated in every competition they participated in. Even in every Olympics as a multi-event sporting event every four years, South Korea's presence in the sport of archery cannot be underestimated. This study aims to find out how to use South Korea's Archery Instagram is at the 2020 Tokyo Olympics in the perspective of technological determinism. The method used in this study is Krippendorff's content analysis with a quantitative approach on Instagram @koreaarchery_official for the period July 23, 2021 to July 31, 2021. The conclusion of this study is that Instagram @koreaarchery_official is used to give appreciation to South Korean archers and raise sportsmanship in digital society and Korean society. South in particular during the Tokyo 2020 Olympics.
\end{abstract}

Keywords: Archery, south korea, 2020 tokyo olympics, media, sports.

\section{PENDAHULUAN}

Olimpiade adalah acara multi-olahraga internasional empat tahunan yang dirayakan sebagai festival olahraga global oleh orang-orang di seluruh dunia. Olimpiade diadakan di musim panas dan musim dingin dengan tujuan untuk membina manusia dan perdamaian dunia melalui olahraga (Olympics.com, 2020a); (Yan, 2020). Pada tahun 1896, Olimpiade modern pertama diadakan di Athena, Yunani, dan pada tahun 1924, edisi musim dingin pertama diadakan di Chamonix, Prancis. Sejak tahun 1994, Olimpiade telah berganti-ganti antara edisi musim panas dan musim dingin setiap dua tahun selama jangka waktu empat tahun masing-masing Olimpiade. (IOC, 2021). Olimpiade telah diselenggarakan sebanyak 32 kali dimana untuk Olimpiade ke-32 diselenggarakan di Tokyo, Jepang.

Olimpiade Tokyo 2020 adalah Olimpiade pertama yang ditunda karena epidemi, yaitu COVID-19, bukan perang atau masalah keamanan, yang menjadi alasan penundaan sebelumnya (Gunawan, 2020); (Hayes, 2020);(Susilo \& Putranto, 2021). Sebanyak 206 kontingen dari 205 negara berpartisipasi dalam Olimpiade Tokyo 2020, dengan satu kontingen unik, Tim Olimpiade Refuge, sehingga jumlah keseluruhan kontingen menjadi 206. Kemudian ada lebih dari 11 ribu atlet yang bersaing di 46 cabang olahraga, termasuk olahraga populer seperti atletik, renang, sepak bola, bulu tangkis (Jati, 2021). Selain itu cabang olahraga lain seperti Panahan yang juga diikuti oleh tim Indonesia tidak tertinggal euforianya dengan menempatkan tim Panahan Korea Selatan yang berada di puncak klasemen.

Panahan adalah olahraga kuno dengan sejarah panjang dan pertama kali digunakan untuk berburu daripada sebagai hobi (Maxson, 2013). Selain itu, Panahan digunakan untuk pertahanan diri, terutama dalam pertempuran pada saat itu, dan sebagai olahraga untuk anggota kerajaan selain berburu (Hitti, 
2002). Sebelum memiliki keterampilan dan keahlian memelihara ternak, Panahan menjadi teknik yang efektif untuk mendapatkan nutrisi berupa protein hewani. Panahan tidak berkembang di satu wilayah, tetapi di banyak wilayah, sehingga ada banyak jenis kompetisi bersejarah untuk kegiatan ini (Nauright, 2012).

Panahan bukan lagi olahraga yang diperuntukkan bagi bangsawan, melainkan untuk atlet. Panahan telah menjadi bagian dari Olimpiade sejak tahun 1900, terlepas dari kenyataan bahwa tidak ada aturan resmi di seluruh dunia saat ini (Nauright, 2012). Panahan merupakan olahraga yang populer di Indonesia, dan telah melahirkan beberapa atlet papan atas dunia (Indahwati \& Ristanto, 2016). Panahan pertama kali dipertandingkan di Olimpiade di Paris pada tahun 1900, dan kembali ditampilkan pada tahun 1908 dan 1920. Namun, aturannya bervariasi dan sepenuhnya tergantung pada negara tuan rumah, yang membuat segalanya menjadi sulit bagi para peserta. Olahraga modern dihidupkan kembali di Munich 1972, setelah 52 tahun absen, dan tetap menjadi program Olimpiade sejak saat itu. Para atlet akan bertanding di nomor tunggal putra dan putri, beregu putra dan putri, dan beregu campuran di Tokyo 2020. Acara beregu campuran merupakan tambahan yang relatif baru dalam jadwal Olimpiade (Olympics.com, 2020b).

Selama perhelatan Olimpiade, Korea Selatan mendominasi perolehan medali dengan 26 medali emas, Korea Selatan juga memimpin di Olimpiade Tokyo 2020, termasuk dua medali emas di dua hari pertama kompetisi. Korea Selatan memenangkan medali emas pertamanya di acara beregu campuran, dan pada hari selanjutnya, Korea Selatan memenangkan medali emas kesembilan berturut-turut di acara beregu putri. Lapangan Panahan Taman Yumenoshima diduplikat dari tempat Olimpiade, didirikan di dalam Pusat Pelatihan Nasional Jincheon di Jincheon, sekitar 90 kilometer selatan Seoul, oleh Asosiasi Panahan Korea. Asosiasi Panahan Korea telah mendirikan tempat pelatihan di pulau selatan untuk mempersiapkan pemanah untuk kondisi berangin di Tokyo (Yonhap, 2021).

Korea Selatan menyapu bersih medali emas pada cabang olahraga Panahan di Olimpiade Rio tahun 2016 empat tahun lalu (Al-Yamani, 2021). Pada Olimpiade Tokyo 2020, Korea Selatan masih tidak terkalahkan pada cabang Panahan setelah meraih medali emas nomor beregu putra (Jawapos.com, 2021). Kompetisi Panahan di Olimpiade Tokyo 2020 berlangsung di Yumenoshima Park pada 23-31 Juli
2021. Ada lima perebutan medali untuk pemanah recurve: individu putra dan putri, beregu putra dan putri, dan tim campuran yang melakukan debutnya di Olimpiade. Ini adalah jumlah medali tertinggi dalam olahraga sejak kembali ke program pada tahun 1972 (Worldarchery, 2021). Pada Minggu, 25 Juli 2021, tim Panahan wanita Korea Selatan mencetak rekor baru dalam sejarah Olimpiade. Mereka tidak hanya meraih medali emas kedua di cabang Panahan, tetapi juga meraih medali emas di beregu campuran sehari sebelumnya. Medali emas kedua mereka juga mengukuhkan dominasi mereka di tim putri pada sembilan Olimpiade terakhir, sejak Olimpiade Seoul 1988 (AlYamani, 2021);(Azizah, 2021). Sehingga pada Olimpiade Tokyo 2020, tim Panahan Korea Selatan mendominasi perolehan medali dengan raihan 4 medali emas dari 5 medali emas yang diperebutkan. Keempat medali tersebut diperoleh dari nomor beregu campuran, beregu putri, beregu putra, dan individu putri.

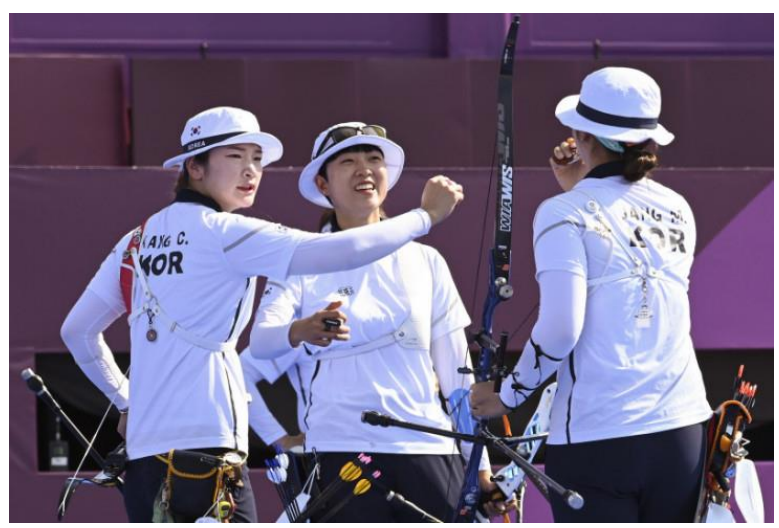

Sumber: (Sidik, 2021)

Gambar 1. Tim panahan putri korea selatan pada olimpiade tokyo 2020

Nomor beregu campuran mulai diperlombakan sebagai bagian dari kampanye kesetaraan seperti cabang-cabang olahraga lainnya dalam olimpiade dan dibidik oleh tim Korea Selatan. Salah satu kekuatan dari Panahan Korea Selatan adalah persaingan yang sengit. Korea Selatan memandang Panahan sebagai sebuah industri dan Panahan di Korea Selatan terdapat sampai 30 tim yang bertanding di dalam sebuah liga. Keberadaan tersebut membuat Korea Selatan memiliki sekitar 140 pemanah yang professional sehingga atmosfer dalam kompetisi Panahan di Korea Selatan menjadi sulit dan terlihat kejam. Ketika ketegangan di semenanjung Korea meningkat pada 1970an, kediktatoran Korea Selatan mengamanatkan bahwa anak laki-laki belajar taekwondo sementara anak perempuan belajar memanah. Fasilitas saat itu masih sangat minim. Tidak hanya buruk dan tidak mencukupi, tetapi juga kekurangan dana. Namun, men- 
jelang Olimpiade Seoul 1988, presiden menginstruksikan para pemimpin perusahaan untuk membiayai federasi olahraga nasional untuk memastikan bahwa olahraga tersebut menerima skor setinggi mungkin. Grup Hyundai telah ditugaskan untuk mempromosikan Panahan di Korea Selatan dan mendapatkan uang untuk olahraga tersebut. Hyundai juga mengirim tim peneliti top untuk melakukan penelitian ilmiah tentang bagaimana meningkatkan kinerja Panahan (Sidik, 2021).

Dominasi Panahan Korea Selatan di tingkat dunia menjadi poin utama penelitian ini yang berfokus pada penggunaan media Instagram. Media yang memiliki efek dalam kehidupan manusia membuat peneliti ingin menggali lebih jauh efek yang muncul dari penggunaan media. Sehingga berdasarkan latar belakang tersebut, penelitian ini bertujuan untuk mengetahui bagaimana penggunaan Instagram Panahan Korea Selatan pada Olimpiade Tokyo 2020 dalam perspektif determinisme teknologi.

\subsection{Penelitian terdahulu}

Munculnya acara olahraga internasional sebagai tontonan media telah menawarkan salah satu daya Tarik terhadap identitas nasional sepanjang abad kedua puluh. Surat kabar, serta lembaga penyiaran swasta dan publik, telah memainkan peran penting dalam proses ini (Mauro, 2020). Olahraga telah menyentuh kehidupan masyarakat dengan cara yang unik, sehingga berkomunikasi dan memasarkan olahraga melalui media sosial juga memerlukan pendekatan yang unik (Newman et al., 2017). Selain itu, media juga turut menentukan perkembangan olahraga, salah satunya media massa yang dapat berkontribusi terhadap corak cabang olahraga tertentu (Santoso, 2013). Media massa juga berperan penting untuk menumbuhkan citra merek terhadap produk tertentu pada konsumen melalui tayangan acara olahraga (Sukarmin, 2010). Media sosial tidak kalah penting dalam strategi promosi olahraga (Reftari et al., 2018). Penelitian-penelitian terdahulu terkait media dan olahraga masih terfokus pada penyiaran dan olahraga secara umum. Sehingga dalam penelitian ini fokus dalam media dan olahraga akan digali dari lebih khusus ke dalam satu cabang olahraga (Panahan) dan satu media saja (Instagram).

\subsection{Instagram}

Instagram adalah program media sosial yang populer di kalangan pengguna smartphone. Nama Instagram berasal dari kata Insta, yang berarti "instan", dan gram, yang berarti "telegram". Akibatnya, Instagram dibuat dari istilah Telegram Instan. Ungkapan tersebut dapat dipahami sebagai sebuah aplikasi yang memungkinkan Anda untuk menyampaikan informasi secara cepat, khususnya dalam bentuk gambar, yang dapat Anda kelola, modifikasi, dan publikasikan ke jaringan media sosial lainnya (Ghazali, 2016).

Instagram adalah produk dari evolusi internet dan diakui sebagai salah satu platform media sosial paling populer saat ini. Pengikut Instagram Pariwisata dapat membuktikan hal ini setiap tahun. Instagram menyatakan pada April 2017 bahwa pengguna aktif bulanannya telah melampaui 800 juta akun, meningkat signifikan dibandingkan tahun sebelumnya. Instagram adalah platform media sosial yang memungkinkan pengguna untuk berbagi foto dengan pengikut mereka atau pengguna Instagram lainnya. Platform ini terutama digunakan oleh pelajar dan mahasiswa di kelas menengah ke atas, karena pengguna Instagram memiliki ponsel untuk mengakses platform dan kamera DSLR untuk mencari bahan untuk dimasukkan ke dalam media Instagram-nya. tentang remaja yang menggunakan media sosial pada umumnya Instagram adalah remaja yang ingin selalu populer; Selain itu, seorang remaja yang menggunakan Instagram memiliki pengetahuan dan kemahiran dengan peralatan yang sangat penting bagi mereka, seperti kamera dan ponsel pintar (Irawan \& Yusuf, 2017).

Instagram saat ini adalah aplikasi media sosial paling populer di kalangan anak muda di seluruh dunia. Lebih dari $70 \%$ orang berusia antara 12 dan 24 tahun adalah pengguna Instagram (Huang \& Su, 2018). Sejak diperkenalkan pada 2010, Instagram telah menjadi pusat budaya digital global, menjadikan selfie, filter, dan bingkai persegi sebagai bagian tak terhindarkan dari kehidupan sehari-hari (Leaver et al., 2020). Namun, penelitian yang berkaitan dengan penggunaan Instagram sebagai bagian dari media sosial belum banyak dikaitkan dengan olahraga. Sekalipun dikaitkan dengan bidang olahraga, topik yang dibahas lebih pada sport branding (Rosyada, 2019), media informasi dan promosi (Wicaksono \& Annissa, 2020), dan media branding (Irwanto \& Arifin, 2021). Sementara pada penelitian ini topik yang dibahas lebih ditekankan pada penggunaan Instagram yang ditinjau menggunakan teori determinisme teknologi.

\subsection{Teori determinisme teknologi}

McLuhan pertama kali mengajukan teori determinisme teknologi dalam makalah tahun 1962 ber- 
judul The Guttenberg Galaxy: The Creation of Human Typography. Premis dari teori ini adalah bahwa perubahan dalam berbagai mode komunikasi akan mempengaruhi keberadaan manusia dengan sendirinya. Teknologi memengaruhi cara orang berpikir dan bertindak dalam masyarakat, dan pada akhirnya teknologilah yang mendorong orang untuk beralih dari satu abad teknologi ke abad berikutnya (McLuhan, 1994); (Meisyaroh, 2013). Menurut McLuhan, media adalah komponen terpenting yang mempengaruhi segalanya. Secara umum, teori determinisme teknologi mencoba menjelaskan bagaimana teknologi, khususnya media, memiliki dampak yang signifikan terhadap bagaimana orang merasa dan bertindak dalam masyarakat.

Pendukung determinisme menganggap bahwa teknologi adalah roda utama perubahan masyarakat, baik secara langsung maupun tidak langsung. Dikenal atau tidak, teknologi memiliki hubungan yang mendalam dengan masyarakat (Ratmanto, 2005). Menurut Marshall McLuhan, cara kita berkomunikasi membentuk budaya kita. McLuhan membagi langkahnya ke dalam beberapa kategori. Sebagai permulaan, kemajuan teknologi komunikasi mengakibatkan pergeseran budaya. Kedua, perubahan gaya komunikasi berdampak pada kehidupan manusia. Ketiga, kita menciptakan peralatan komunikasi, dan peralatan komunikasi yang kita gunakan membentuk atau mempengaruhi kehidupan kita. Karena pesan yang diterima teknologi komunikasi memungkinkan kita untuk belajar, merasakan, dan berpikir tentang apa yang akan kita lakukan, kita pelajari, rasakan, dan pikirkan tentang apa yang akan kita lakukan. Artinya, komunikasi teknologi mengirimkan pesan dan membentuk tindakan kita sendiri. Bahkan McLuhan sampai pada kesimpulan bahwa medium (medium adalah pesan) adalah pesan itu sendiri (Aunillah, 2020).

Menurut McLuhan, media adalah jantung peradaban manusia. Landasan organisasi sosial manusia dan kehidupan kolektif ditentukan oleh dominasi media dalam suatu masyarakat (Saefudin, 2008). Teori determinisme teknologi berkembang seiring dengan kemajuan teknologi komunikasi, yang berdampak signifikan pada pertumbuhan media massa, kontak sosial manusia, dan masuknya internet ke dalam kehidupan sehari-hari. Internet mengubah dunia dan manusia. Pesatnya kemajuan teknologi komunikasi memunculkan media baru yang sering disebut media sosial, yang merupakan media interaktif yang memanfaatkan jaringan internet untuk menghubungkan seluruh dunia.
Karena manusia adalah objek dari teknologi, maka teknologi mengubah pemikiran dan pengambilan keputusan manusia, dan munculnya media baru ini membuat hubungan antar manusia lebih mudah berkembang dalam hal berinteraksi dan memperoleh informasi. Mengingat teknologi terus berkembang dan berperan dalam pengendalian, media sosial dianggap tidak mampu memberikan penyesuaian yang dibutuhkan konsumen.

\section{METODE PENELITIAN}

Metode analisis isi (content analysis) digunakan dalam penelitian ini dengan pendekatan kuantitatif untuk mendeskripsikan unsur dan karakteristik isi postingan. Analisis isi adalah pendekatan sistematis untuk mengevaluasi isi dan transmisi pesan, serta alat analisis untuk memantau dan menganalisis materi yang dapat diakses dari aktivitas komunikasi komunikator terpilih (Kim, 2019). Analisis isi adalah metode ilmiah untuk menganalisis informasi dari media seperti acara televisi, kolom surat kabar, buku, foto, dan internet (Krippendorff, 2018). Peneliti menggunakan dua pembuat kode (coder) untuk memastikan objektivitas dalam pengkodean dan pengumpulan data. Uji reliabilitas digunakan untuk memeriksa keabsahan data yang dikumpulkan dan untuk mengetahui keakuratan data dan dilakukan oleh dua coder. Selain itu, peneliti juga menggunakan content analysis Krippendorff untuk menganalisis postingan Instagram. Peneliti menggunakan analisis isi untuk melihat efek komunikasi di Instagram @koreaarchery_official selama periode 23 Juli 2021 sampai 31 Juli 2021di postingan Instagram @koreaarchery_official, total ada 94 postingan yang diteliti.

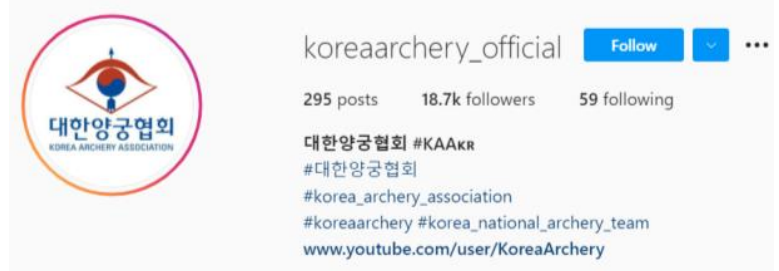

Sumber: (Instagram, 2021)

Gambar 2. Profil instagram korea archery association

Efek adalah perubahan khalayak yang terjadi sebagai akibat dari integrasi pesan media. Di bidang pengetahuan, sikap, dan perilaku nyata, David Berlo mengkategorikan efek atau perubahan. Perubahan perilaku seringkali didahului oleh pergeseran sikap, yang seringkali didahului oleh pergeseran pengetahuan. Efek ditentukan oleh reaksi penonton (audience response), yang dijadikan sebagai umpan balik (input). Akibatnya, umpan balik adalah metode untuk me- 
nentukan efeknya (McQuail, 2011). Efek dari komunikasi memiliki tiga dimensi meliputi kognitif, afektif, dan konatif. Peningkatan kesadaran, pembelajaran, dan pengetahuan adalah beberapa konsekuensi kognitif. Emosi, suasana hati, dan sikap semuanya dipengaruhi oleh efek afektif (sikap). Sedangkan behavioral atau konatif mengacu pada tindakan dan niat seseorang untuk melakukan sesuatu dengan cara tertentu (Sukendar, 2017), sehingga untuk melihat efek komunikasi dalam postingan Instagram @korearchery_official peneliti menggunakan indikator efek kognitif, afektif, dan behavioral.

Efek kognitif dapat terjadi ketika ada perubahan pada apa yang diketahui, menjangkau, atau dipersepsi khalayak. Efek kognitif ini akan dibahas tentang bagaimana media massa bisa membantu khalayak di dalam memahami informasi yang bermanfaat serta mengembangkan keterampilan kognitifnya. Efek afektif lebih kuat daripada efek kognitif. Tujuan komunikasi massa bukan hanya untuk memberitahu publik tentang sesuatu; itu juga untuk membangkitkan emosi seperti kasih sayang, kegembiraan, kesedihan, dan kegembiraan di antara penonton. Efek behavioral adalah merupakan akibat munculnya diri khalayak melalui bentuk perilaku maupun kegiatan. Pernyataan ini berusaha untuk mengungkapkan efek dari komunikasi massa terhadap perilaku, tindakan serta gerakan dari khalayak yang muncul dalam kehidupan sehari-hari (Ardianto, 2014).

Penelitian ini menggunakan rumus Holsti untuk menghitung data yang diperoleh dari kedua coder (Samiei \& Mehrabi, 2019; Alam et al., 2020). Peneliti memilih pendekatan analisis isi karena ingin melihat efek komunikasi dalam postingan Instagram @koreaarchery_official secara kuantitatif, kemudian mengevaluasi konten postingan, membaca simbol, dan menginterpretasikan materi interaksi simbolik yang terjadi pada postingannya. Langkah-langkah peneliti dalam metode analisis isi ini adalah sebagai berikut: 1) Peneliti mengumpulkan postingan Instagram @koreaarchery_official selama periode 23 Juli 2021 sampai 31 Juli 2021, 2) Peneliti memberikan hasil pengumpulan postingan Instagram@koreaarchery_official kepada coder untuk dinilai berdasarkan efek komunikasi yang muncul di setiap postingan, 3) Setelah coder selesai memberi penilaian, data diserahkan kembali ke peneliti, 4) Data yang diperoleh kemudian diolah dan dianalisis.

$$
\mathrm{PAo}=2 \mathrm{~A} /(\mathrm{N} 1+\mathrm{N} 2)
$$

Dimana PAo adalah persentase kesepakatan kedua pembuat kode, A adalah jumlah keputusan yang dibuat oleh kedua coder, N1 dan N2 adalah jumlah keputusan yang dibuat oleh coder.

\section{PEMBAHASAN}

Tabel 1. Coder output

\begin{tabular}{cccc}
\hline \multirow{2}{*}{ Variabel } & \multicolumn{3}{c}{ Coding Output } \\
\cline { 2 - 4 } & Coder 1 & Coder 2 & $\begin{array}{c}\text { Agreement between } \\
\text { two coders }\end{array}$ \\
\hline Kognitif & 46 & 40 & 40 \\
Afektif & 43 & 45 & 43 \\
Behavioral & 5 & 9 & 5 \\
Total & 94 & 94 & 88 \\
\hline
\end{tabular}

$$
\begin{gathered}
\mathrm{Pao}=2 \mathrm{~A} /(\mathrm{N} 1+\mathrm{N} 2)=2(88) / 94+94=176 / 188 \\
=0,93(93 \%)
\end{gathered}
$$

Data dikatakan reliabel jika dapat memiliki nilai toleransi minimal $70 \%$ atau lebih dari $0,7 \%$ (Holsti, 1969). Unsur reliabilitasnya sebesar 0,93 atau $93 \%$ berdasarkan hasil perhitungan data yang diperoleh dengan menggunakan rumus reliabilitas Coder Holsti. Oleh karena itu data yang diperoleh dinyatakan reliabel karena melebihi batas minimal.

Hasil pengkodean telah dilakukan oleh para coder dengan menggunakan tiga indikator meliputi efek kognitif, afektif, dan behavioral dalam postingan Instagram @koreaarchery_official. Hasil pengkodean tersebut didapatkan bahwa indikator afektif mendominasi postingan Instagram @ koreaarchery_ official selama periode 23 Juli 2021 sampai 31 Juli 2021. Postingan yang berkaitan dengan afektif pada periode 23 Juli 2021 sampai 31 Juli 2021 muncul lebih banyak pada 30 Juli 2021.

\subsection{Konsistensi pemanah putri korea selatan}

Dominasi prestasi Panahan Korea Selatan dalam setiap perhelatan Olimpiade kembali dipertahankan dalam Olimpiade Tokyo 2020. Setelah meraih 3 medali emas di nomor beregu campuran, beregu putri, dan beregu putra, tim Panahan Korea Selatan kembali berlaga untuk memperebutkan medali emas pada nomor individu putra dan individu putri. Namun dalam nomor individu, hanya menyisakan An San di sektor putri yang bertahan sampai di final perebutan medali dan berhasil meraih medali emas di nomor individu putri setelah mengalahkan Osipova dari Russian Olympic Committee (ROC) dengan poin 6-5 atas kemenangan An San. 


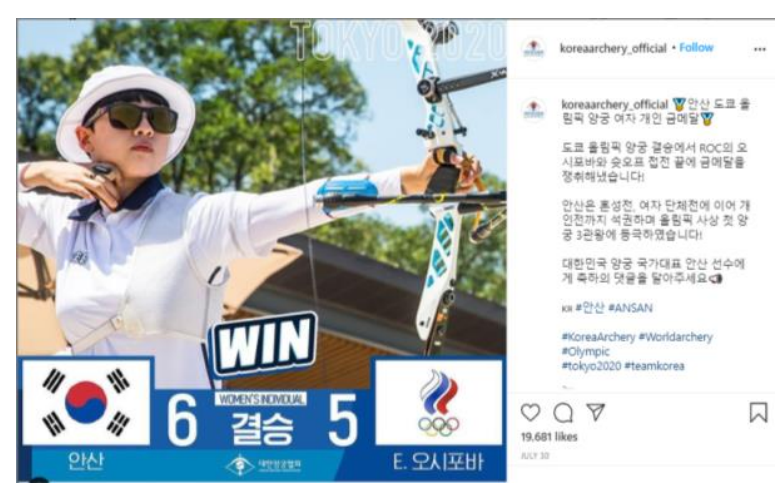

Gambar 3. Kemenangan an san pada nomor individu putri

Pada gambar 3 dapat diamati bahwa dalam postingan Instagram @koreaarchery_official sosok An San banyak muncul di dalam postingan selama perhelatan Olimpiade Tokyo 2020. Hal tersebut tentunya didasari oleh prestasi An San sebagai pemanah Korea Selatan yang terbilang paling sukses dengan meraih 3 medali emas dalam sejarah keikutsertaan tim Panahan Korea Selatan dalam Olimpiade. Kemenangan demi kemenang yang diraih An San maupun pemanah Korea Selatan lainnya di dalam Olimpiade Tokyo 2020 diapresiasi dalam setiap postingan Instagram @ koreaarchery_official dengan memberikan tulisan "WIN" dan ditambahkan keterangan hasil skor antara pemanah Korea Selatan dan lawan-lawannya.

Ditinjau dalam teori determinisme teknologi terkait pemikiran manusia yang dipengaruhi oleh teknologi yang ada, postingan Instagram @koreaarchery_ official terkait An San berusaha mengajak masyarakat untuk berpikir dengan positif dengan memberikan apresiasi yang setinggi-tingginya terhadap prestasi yang telah diraih An San sebagai pemanah putri Korea Selatan tersukses dalam sejarah keikutsertaan Korea Selatan dalam Olimpiade. Pencapaian An San tentunya bukan sebuah hal yang mudah, untuk itulah melalui postingan Instagram @koreaarchery_official cara berpikir masyarakat dibentuk untuk menghargai usaha dan memberi apresiasi yang tinggi.

\subsection{Membangun sportivitas masyarakat digital}

Selain kemenangan An San pada sektor individu putri pada Olimpiade Tokyo 2020 yang mendapat keistimewaan untuk diposting dalam Instagram @ koreaarchery_official, para pemanah Korea Selatan lainnya yang kalah di babak-babak eliminasi tetap mendapatkan apresiasi dalam postingan Instagram @ koreaarchery_official.

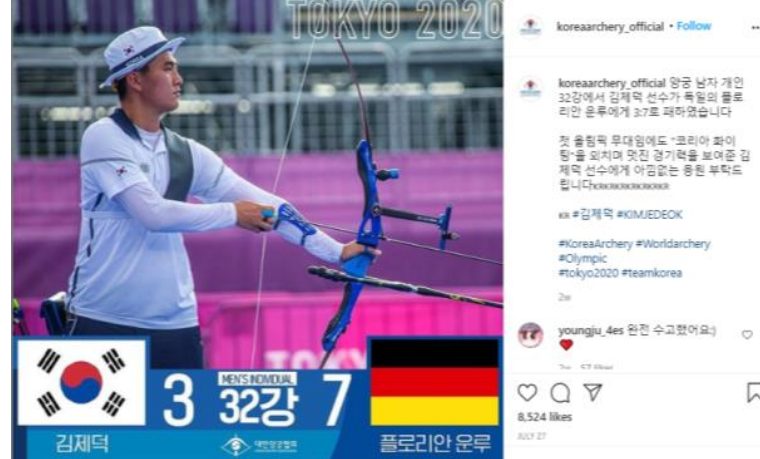

Gambar 4. Kim je-deok

Pemanah Korea Selatan yang terhenti di babak individu putra adalah Kim Je-deok yang terhenti di babak 32 besar Panahan individu putra oleh pemanah Jerman, Florian Unru dengan poin 3-7.

Pemanah Korea Selatan kedua yang terhenti di nomor individu putri adalah Jang Minhee di babak 32 besar Panahan individu putri. Jang Minhee terhenti oleh pemanah Jepang, Miki Nakamura dengan poin 2-6.

Pemanah Korea Selatan ketiga yang terhenti di nomor individu putra adalah Oh Jin Hyek yang terhenti di babak 32 besar Panahan individu putra dari Atanu Das, pemanah India dengan poin 5-6.
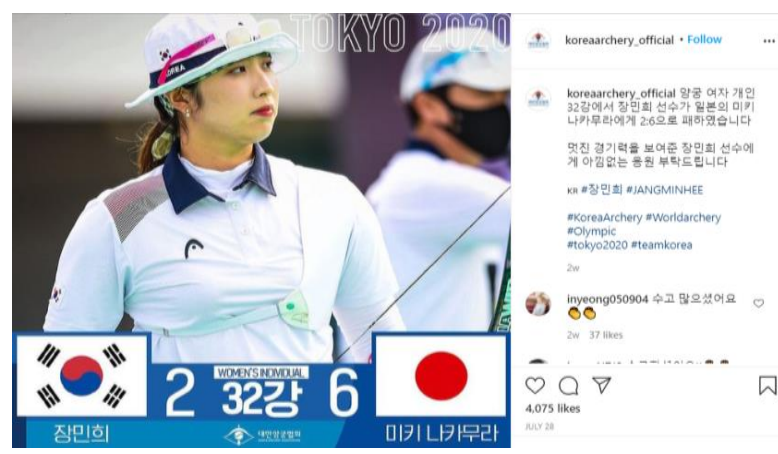

Gambar 5. Jang minhee

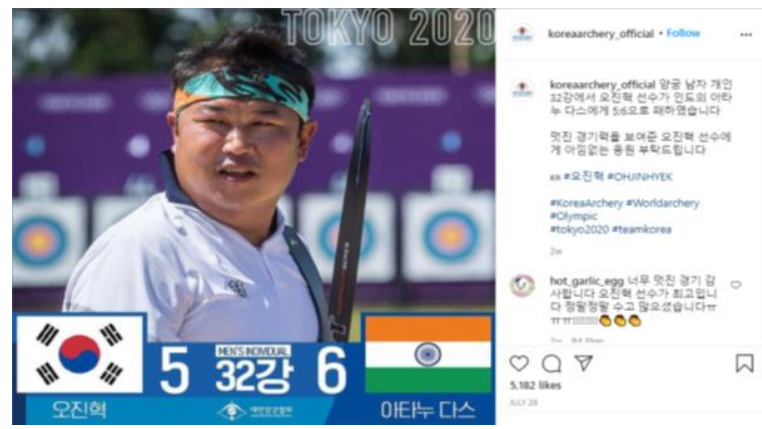

Gambar 6. Oh jin hyek 


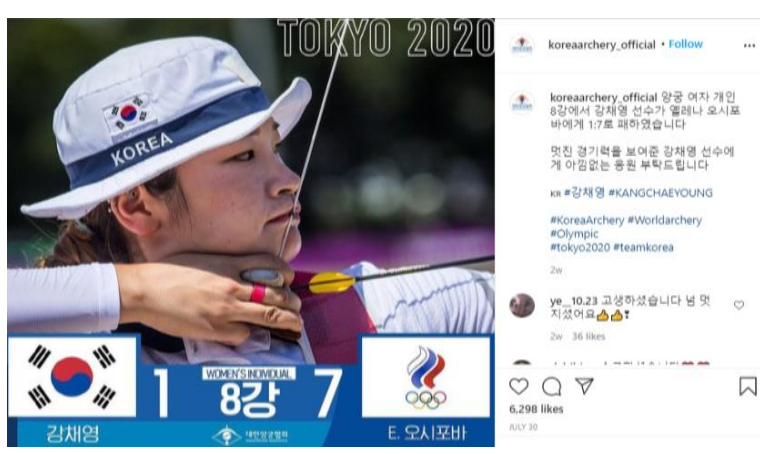

Gambar 7. Kang chae-young

Pemanah Korea Selatan keempat yang terhenti di nomor individu putri adalah Kang Chae-Young yang terhenti di babak perempat final Panahan individu putri dari Jelena Osipova 1-7.

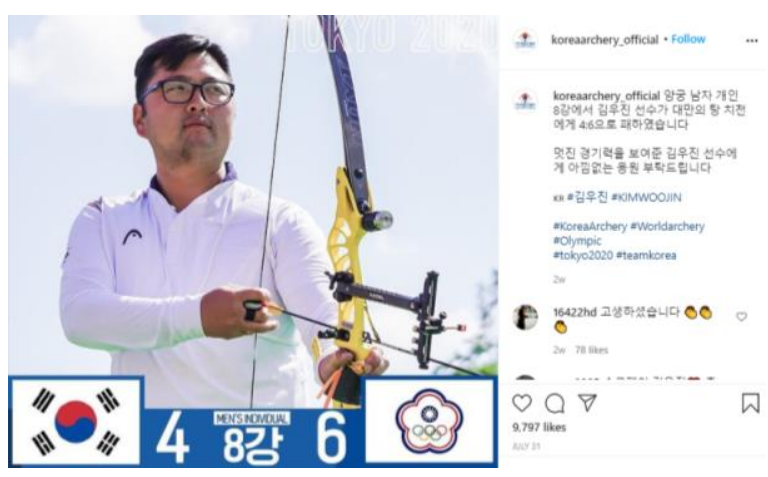

Gambar 8. Kim woojin

Pemanah Korea Selatan kelima yang terhenti di nomor individu putra adalah Kim Woojin yang terhenti di babak perempat final Panahan individu putra dari Tang Chicheon, pemanah Taiwan dengan poin 46.

Pada gambar 4, 5, 6, 7, 8 terlihat postingan dalam Instagram @koreaarchery_official yang memperlihatkan para pemanah Korea Selatan yang tereliminasi dari nomor individu. Meskipun harus terhenti dibabak-babak awal nomor individu, para pemanah Korea Selatan diberikan apresiasi dalam Instagram @koreaarchery_official dengan memposting sosoksosok pemanah yang belum berhasil mencapai final seperti An San. Namun yang membedakan antara An San yang mencapai final dengan para pemanah lain yang kalah dan tidak mencapai final adalah hanya menampilkan poin kekalahannya saja tanpa memberikan tulisan "LOSE".

Ditinjau dari teori determinisme teknologi, pemikiran manusia terutama para pengguna media sosial yang menggunakan Instagram dan melihat postingan Instagram @koreaarchery_official selama perhelatan
Olimpiade Tokyo 2020 digiring untuk menggugah sportivitas tidak hanya para pemanah yang berlaga dalam Olimpiade Tokyo 2020, namun juga bagi masyarakat digital utamanya masyarakat Korea Selatan sebagai bagian dari representasi Panahan Korea Selatan. Kekalahan yang umumnya memunculkan kekecewaan masyarakat dalam sebuah kompetisi, digiring oleh postingan Instagram @ koreaarchery_ official agar tidak memicu munculnya kekecewaan masyarakat dan membuat semangat para atlet untuk semakin tangguh atas apresiasi yang diberikan melalui postingan Instagram @koreaarchery_official.

\section{SIMPULAN}

Berdasarkan analisis data yang telah dilakukan menunjukkan bahwa postingan Instagram @koreaarchery_official selama Olimpiade Tokyo 2020 berisi berita kemenangan dan kekalahan pemanah-pemanah Korea Selatan. Ditinjau dari teori determinisme teknologi yang berasumsi bahwa teknologi mempengaruhi pemikiran manusia, hal tersebut dimaksudkan agar kemenangan maupun kekalahan pemanah-pemanah Korea Selatan yang muncul melalui postingan Instagram bertujuan untuk membangun apresiasi dari masyarakat selama Olimpiade Tokyo 2020. Selain itu, ditinjau dari asumsi pemikiran manusia terutama para pengguna media sosial, postingan Instagram @ koreaarchery_official berusaha untuk menggiring upaya kekecewaan dan pengecaman masyarakat atas kekalahan dengan mempengaruhi pemikiran pengguna media sosial (Instagram) dan masyarakat Korea Selatan pada khususnya agar memiliki sikap sportivitas.

\section{DAFTAR PUSTAKA}

Al-Yamani, Z. (2021). Sejarah Panjang Dominasi Korsel di Panahan Olimpiade. https://www. viva.co.id/sport/gelanggang/1390231-sejarahpanjang-dominasi-korsel-di-panahan-olimpiade

Alam, W., Marijan, K., Aminah, S., \& Putranto, T. (2020). Drug eradication in indonesian millennials through school visits. Journal of Drug and Alcohol Research, 9(1), 1-6. https://doi.org/ 10.4303/jdar/236089.

Ardianto, E. (2014). Komunikasi Massa Suatu Pengantar. Bandung: Simbiosa Rekatama Media.

Aunillah, R. (2020). Determinisme Teknologi: Perayaan Idul fitri di Saat Pandemi. Journal of Islamic Comunication, 3(1).

Azizah, N. (2021). Korea Selatan Dominasi Emas Panahan Olimpiade Tokyo. https://www.republika.co.id/berita/qwsz9m463/korea-selatandominasi-emas-panahan-olimpiade-tokyo 
Ghazali, M. (2016). Buat Duit Dengan Facebook dan Instagram: Panduan Menjana Pendapatan dengan Facebook dan Instagram. Malaysia: Publishing House.

Gunawan, A. (2020). 5 Dimensi Dampak Kebijakan Covid-19 Terhadap Sistem Keolahragaan Nasional. Jejaring Administrasi Publik, 12(1), 23-42.

Hayes, M. (2020). Social media and inspiring physical activity during COVID-19 and beyond. Managing Sport and Leisure, 1-8.

Hitti, P. (2002). History of The Arabs: From the Earliest Times to the Present. New York, NY: Palgrave Macmillan.

Holsti, O. (1969). Content analysis for the social sciences and humanities. Reading, MA: Addison-Wesley.

Huang, Y.-T., \& Su, S.-F. (2018). Motives for Instagram use and topics of interest among young adults. Future Internet, 10(8), 77.

Indahwati, N., \& Ristanto, K. (2016). The application of pettlep imagery exercise to competitive anxiety and concentration in Surabaya archery athletes. International Journal of Educational Science and Research (IJESR), 6(3).

Instagram, K. (2021). Profil Instagram Korea Archery Association. https://www.instagram. com/koreaarchery_official/

IOC. (2021). The modern Olympic Games are the world's foremost multi-sports event. https://olympics.com/ioc/celebrate-olympic-games.

Irawan, E., \& Yusuf, Y. (2017). Instagram Sebagai Gaya Hidup Masyarakat Kota Pekanbaru (Studi Komunitas Instagram Di Kota Pekanbaru). Riau University.

Irwanto, D., \& Arifin, M. (2021). Strategi Persela dalam Menggunakan Instagram sebagai Media Branding Klub di Musim Kompetisi Shopee Liga 1 2019. Jurnal Prestasi Olahraga, 4(3), $129-135$.

Jati, A. (2021). Daftar Lengkap Cabang Olahraga yang Dipertandingkan di Olimpiade Tokyo 2020. https://www.bola.com/ragam/read/46158 04/daftar-lengkap-cabang-olahraga-yangdipertandingkan-di-olimpiade-tokyo-2020.

Jawapos.com. (2021). Korea Selatan Menggila di Cabang Panahan Olimpiade Tokyo 2020. https://www.jawapos.com/sports/26/07/2021/ko rea-selatan-menggila-di-cabang-panahan-olimpiade-tokyo-2020/

Kim, H. (2019). Globalization and regulatory change: The interplay of laws and technologies in Ecommerce in Southeast Asia. Computer Law and Security Review, 35(5), 1-20. https://doi. org/10.1016/j.clsr.2019.03.009
Krippendorff, K. (2018). Content analysis: An introduction to its methodology. Sage Publications.

Leaver, T., Highfield, T., \& Abidin, C. (2020). Instagram: Visual social media cultures. John Wiley \& Sons.

Mauro, M. (2020). Media discourse, sport and the nation: Narratives and counter-narratives in the digital age. Media, Culture \& Society, 42(6), 932-951.

Maxson, L. (2013). The archery: The history of archery series. Worcestershire: Read Books Ltd.

McLuhan, M. (1994). Understanding media: The extensions of man. London: The MIT Press.

McQuail, D. (2011). Teori Komunikasi Massa, Edisi 6 Buku 1. Jakarta: Salemba Humanika.

Meisyaroh, S. (2013). Determinisme Teknologi Masyarakat dalam Media Sosial. Jurnal Komunikasi Dan Bisnis, 1(1). https://jurnal.kwikkiangie.ac.id/index.php/JKB/article/view/59

Nauright, J. (2012). Sports around the World: History, Culture, and Practice [4 volumes]: History, Culture, and Practice. Abc-Clio.

Newman, T., Peck, J., \& Wilhide, B. (2017). Social media in sport marketing. Routledge.

Olympics.com. (2020a). About the Olympic Games. https://olympics.com/tokyo-2020/en/games/ olympic-games-about/

Olympics.com. (2020b). Archery overview. https:// olympics.com/tokyo-2020/en/sports/archery/

Ratmanto, T. (2005). Determinisme Teknologi dalam Teknologi Komunikasi dan Informasi. Mediator, 6(1).

Reftari, D., Suryana, A., \& Setiaman, A. (2018). Komunikasi Pemasaran Olahraga Renang. Jurnal Kajian Komunikasi, 6(2), 247-260.

Rosyada, S. (2019). Sports Branding di Media Sosial (Studi Kasus Pemanfaatan Instagram dalam Kegiatan Sports Team Branding Vamos FC Mataram sebagai Klub Futsal Profesional Indonesia di tahun 2018). Universitas Gadjah Mada.

Saefudin, A. (2008). Perkembangan Teknologi Komunikasi: Perspektif Komunikasi Peradaban. Jurnal Mediator, 9(2).

Samiei, D., \& Mehrabi, Z. (2019). Content analysis of the first chapter of the twelfth grade chemistry book based on the william romey's method and determining its importance with the shannon entropy method. 1(3), 53-72. https://www.sid.ir/ en/journal/ViewPaper.aspx?ID=720429

Santoso, T. (2013). Peran Media Massa dalam Olahraga. Jurnal Ilmiah Spirit, 13(1).

Sidik, J. (2021). Mengapa Korea Selatan begitu mendominasi panahan Olimpiade. https://www. antaranews.com/berita/2288054/mengapakorea-selatan-begitu-mendominasi-panahanolimpiade? page $=2$. 
Sukarmin, Y. (2010). Pemasaran olahraga melalui berbagai event olahraga. Medikora, 6(2).

Sukendar, M. (2017). Psikologi Komunikasi: Teori dan Praktek. Yogyakarta: CV Budi Utama.

Susilo, D., \& Putranto, T. (2021). Olympic Games 2020: Discourse of the Japanese Government after Postponed in japantimes.co.jp. Jurnal Kajian Media, 5(1). https://doi.org/https://doi. org/10.25139/jkm.v5i1.3504.

Wicaksono, A., \& Annissa, J. (2020). Pemanfaatan Instagram Akun@ Futsal_UBL Sebagai Media Informasi dan Promosi Futsal Universitas Budi Luhur. PANTAREI, 4(03).
Worldarchery. (2021). Tokyo 2020 Olympic Games. https://worldarchery.sport/competition/14904/to kyo-2020-olympic-games?photos_tag=17 JULY VENUE.

Yan, W. (200). Olympic Games as a Digital Media Product. Marketing and Management of Innovations, 3, 306-318. https://doi.org/http://doi. org/ 10.21272/mmi.2020.3-22

Yonhap. (021). [Tokyo Olympics] Why is S. Korea so good at archery? Athletes find answer in transparency, internal competition. http://www. koreaherald.com/view.php?ud=2021072600055 8. 